\title{
Scar Contractures
}

Marguerite Guillot Masanovic and Luc Téot

\section{Contents}

13.1 Introduction - 118

13.2 General Features -118

13.3 Contractures of the Neck - 118

13.4 Axillar Contractures - $\mathbf{1 1 9}$

13.5 Hand Contractures - 119

13.6 Other Anatomical Sites of Scar Contractures - 120

13.7 Rehabilitation Programs - 120

13.8 Surgical Strategies -121

13.9 Z Plasties - 121

13.10 Skin Grafts - 121

13.11 Dermal Substitutes - 121

13.12 Flaps -121

13.13 Conclusion -122

References - 122 


\subsection{Introduction}

The prevalence of contractures is high, especially after burns and may vary, depending on the age, the depth of the initial burns, and the time between burns and the occurrence of the contractures. Young patients and children are more likely candidates to develop contractures. When skin grafting after burn is performed in due time, the prevalence is lower. Contractures are more likely to occur in more severe burns, flame burns, children, females, on the cervical spine and in the upper extremity. The absence of physiotherapy and an abnormal long period awaiting spontaneous healing without skin grafting will progressively induce severe contractures. This is still frequently observed on the upper limbs in burn patients in developing countries. Early excision and skin grafting is the best option to reduce the incidence of contractures. Other causes of contractures are less frequently observed, but may be seen after trauma or infection, linked to noncompliance, a too long immobilization, a joint destruction, an epiphysiodesis in children. This chapter proposes to give an overview of the functional limitations of the skin contractures and the need for an adapted early rehabilitation program starting during the healing stage and carried on during the next 2 years post burns and other causes of skin limitation.

\subsection{General Features}

Incidence of contractures has been recently analyzed [1, 2] on patients presenting acute burns across or adjacent to the neck, shoulder, elbow, wrist, hip, knee, and ankle. Passive range of motion was measured at 3-6-9-12 months after burn. Limited range of motion of non-operated burned joints was restored back to normal within 6-9 months. From the operated burned joints, 58.6\% demonstrated a limited range of motion at 3-6 weeks declining to $20.9 \%$ at 12 months. The upper part of the body was affected more often by scar contracture than the lower part. Reconstructive surgery was performed in $13.3 \%$ of the operated burned joints. This study confirms that a quick skin grafting is a good option to prevent severe contractures, but not enough to prevent all of them.

Contractures may clinically present with different characteristics, like bands of skin partially limiting the range of joint movements to a complete impossibility to move, all joints being glued in deep stiffness. Contractures are more or less severe, depending if the deep structures (tendons, aponeurosis, subcutaneous muscles, or fascia) are involved in the process, and the type of contracture, static or dynamic.

Skin capacity is particularly limited in burns of the dorsal aspect of the hand, if an adapted rehabilitation program including staged splinting of the hand before, during, and after skin grafting, as well as slow movements during the inflammation stage and more active after some months is not properly done. The usual limitation is observed at the level of the metartarsophalangeal joints (in flexion) and the grip is impacted.

Contractures may variably limit the amplitude of movements, some of them being only observed during full movements, others imposing a severe stiffness and a blockade of any movement. Neck contractures may simply affect the extreme degrees of lateral movements or realize a vertical contracture (chin to thorax) imposing strong difficulties to maintain the horizontal sight, a situation extremely difficult to live with.

Web contractures may limit multidirectional movements on the neck or the shoulder, others will limit opening of orifices (mouth, nostrils, perineal areas) with concentric contractures, a cause of difficulties to feeding.

Contractures may vary along time. An early inflammation is frequently observed in children or young adults after burns, lasting some months especially on mobile areas like the thorax and the upper limb. This situation may be transiently observed during the first 2 years and may disappear afterward. This period should be covered by adapted physiotherapy programs, aiming at an augmented range of movements and a less red skin.

\subsection{Contractures of the Neck}

Neck skin is extremely mobile over the underlying structures. This mobility will be quickly limited in burns, due to a skin retraction linked to wound healing and particularly to the mechanical action of myofibroblasts, but also to the pain during movements inducing a voluntary restriction of movement during the healing stage. These combined factors induce a centripetal retraction and may lead to different situations, ranging from a single line of skin tension in the lateral movements (- Fig. 13.1) to severe vertical and horizontal loss of movements. The subcutaneous muscles, embedded in the scarring process,



Fig. 13.1 Neck contracture persistent in spite of several surgical procedures 
contribute to skin limitation. In severe situations the horizontal sight may be impacted, bending permanently the neck and imposing a difficult surgery.

\subsection{Axillar Contractures}

Three different areas may be impacted by retractile scars, the anterior and posterior pillars, and the central axilla. Skin contractures may affect any one or the three of these areas, with different possible extensions on the anterior or posterior thorax. The shoulder is mobile anteriorly, posteriorly, and laterally, needing a full skin mobility in all aspects of the region. A large range of functional deficits may be encountered in burns, with a good reactivity to early physiotherapy and specifically to range axilla orthotic, as demonstrated [3] (• Figs. 13.2, 13.3, and 13.4).

\subsection{Hand Contractures}

Burns usually affect the dorsal aspect of the hand, with a centripetal retraction impairing the complete combined flexion of all digits together. The deficit in terms
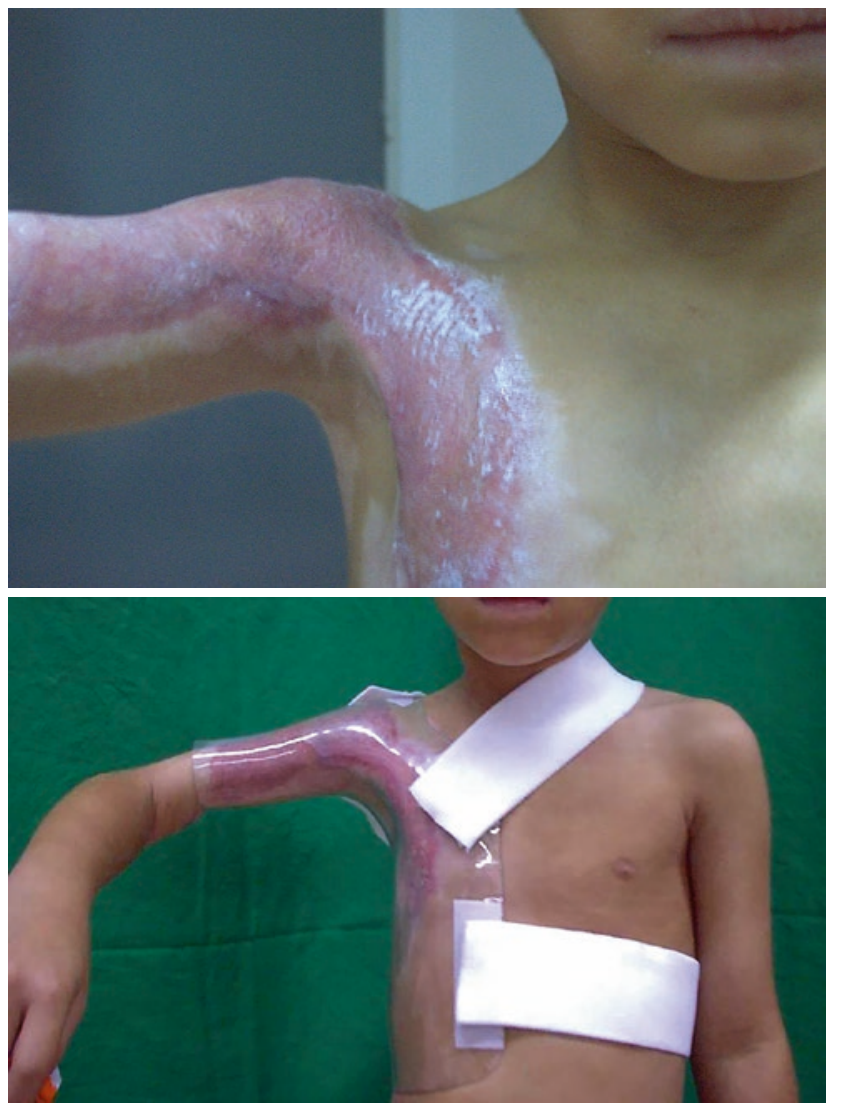

- Figs. 13.2 and $\mathbf{1 3 . 3}$ Postburn axillar contracture treated by an orthotic orlen realized at fashion

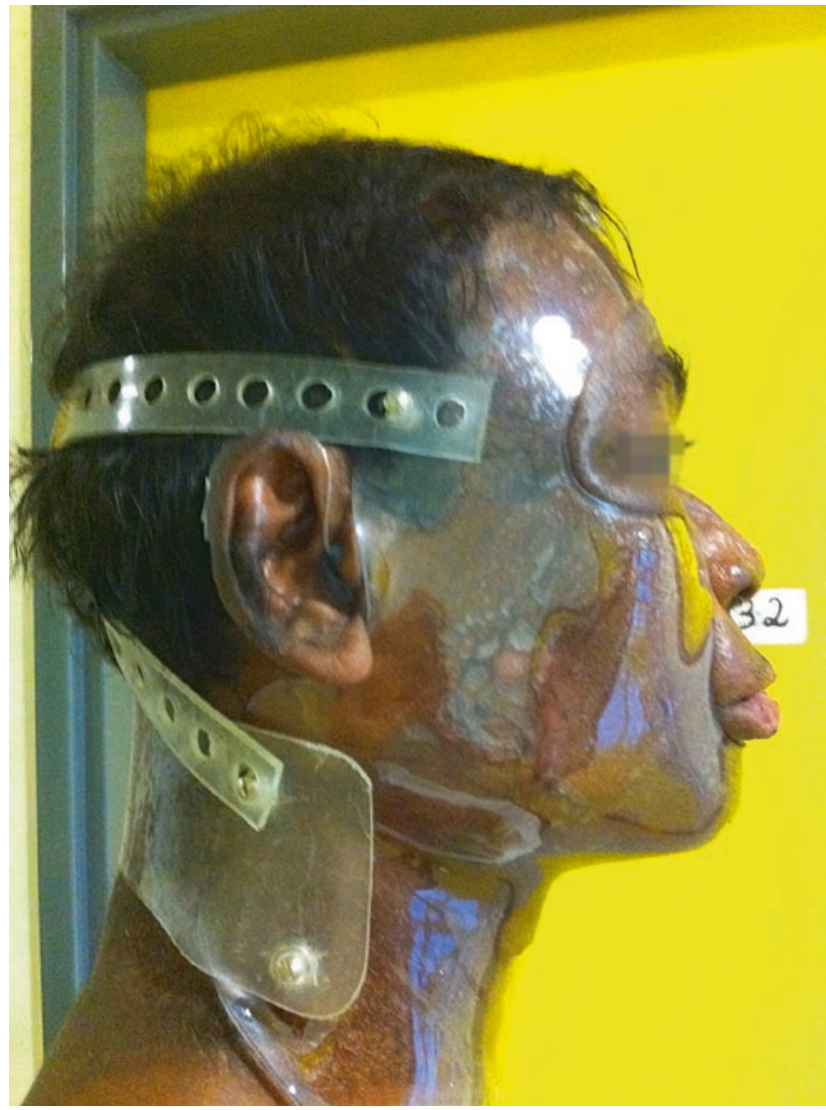

- Fig. 13.4 Severe postburn neck contracture on a young female treated by an orthesis worn initially $24 / 7$ during 2 months and then at night

of grip may be crucial; other situations may limit one or two digits in flexion. When the situation has become chronic, tendon shortening and bone deformities may be observed, imposing complex surgical procedures including bone shortening, joint arthrodesis, and tendon lengthening to restore function.

The dorsal aspects of the interdigital webs are frequently involved, with consequences on the separate movements of each digit, a quadrige effect often observed in poorly managed deep burns.

The palmar aspect of the hand is less frequently touched but more frequent in children, but the very deep scarring tissues may sometimes reach more than $2 \mathrm{~cm}$ depth, inducing tendons blockade. Usually these severe scars embed totally the underlying structures, nerves, vessels, tendons, and muscles (• Fig. 13.5).

Persistent contractures observed in young adults having been submitted to burns that occurred during childhood, with retracted wrists and elbows or completely locked axillas, which sometimes require bone resection or amputation, are less observed now with the development and diffusion of NGO programs acting in underdeveloped countries. 


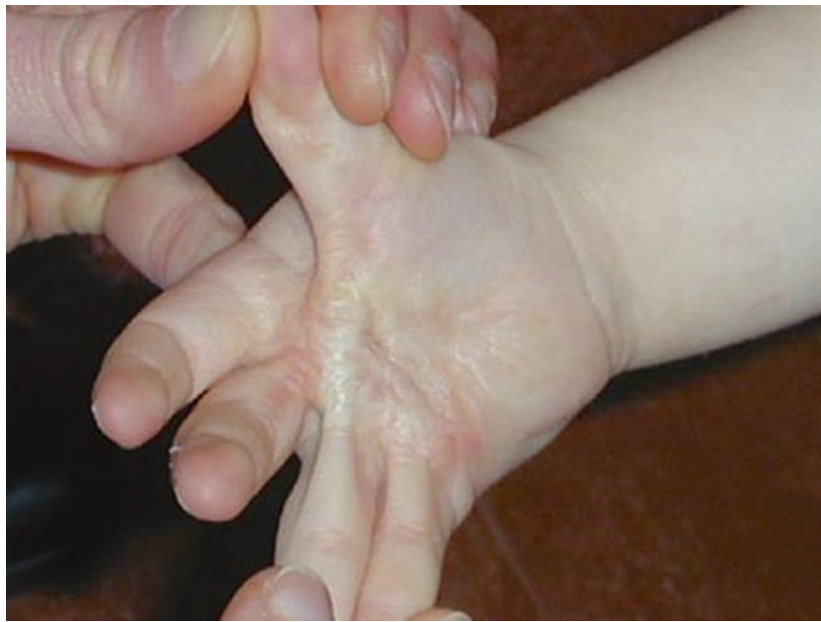

- Fig. 13.5 Palmar contracture embedding the whole palmar area, creating a maximal web between the I and the IV. Surgery is needed

\subsection{Other Anatomical Sites of Scar Contractures}

Lower limbs may develop contractures at the level of hips (in flexion), knee, and foot (dorsal positioning of toes). These contractures are better managed by an adapted rehabilitation, completed by surgical procedures if needed.

\subsection{Rehabilitation Programs}

During the wound-healing stage, splinting of the burned hands, the neck, the axillar, and the lower limbs are needed to prevent contractures. Most of the burns centers benefit of a specific rehabilitation team included in the organization of the center. Passive movements during the dressing change and positioning of joints into adapted customized splints in position of maximum extension capacity will efficiently limit the development of contractures (- Fig. 13.6). Exercise is allowed as soon as the inflammatory period is under control, immobilization being the most anti-inflammatory agent.

After skin closure, active and passive movements will be encouraged but it is essential not to exert an excessive mechanical tension on contractures, relayed and completed by the design of compressive garments, and mechanical compression of the involved areas. Specific rehabilitation centers for severely burned patients exist in some countries, proposing multiprograms to soften the scar, manipulate joints, and efficiently prevent the occurrence of the contractures using positioning, especially on the axillar region, the neck, and the hands (• Figs. 13.7 and 13.8).

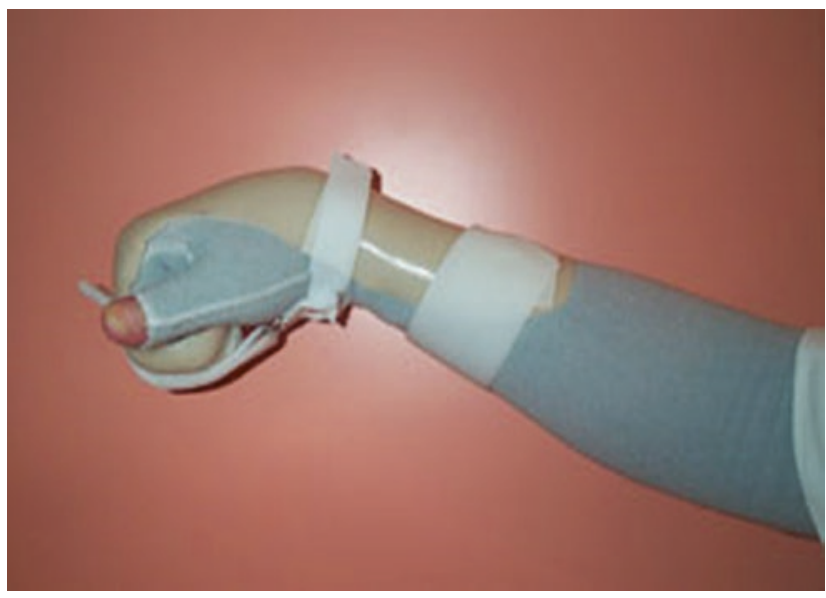

- Fig. 13.6 Hand splint in complete digital flexion used for mechanical tension over the dorsal aspect



- Fig. 13.7 Hand splint in complete digital extension used for mechanical tension on the palmar aspect. In case of contracture touching both the aspects of the hand, alternative positioning in flexion during night and in extension during the day may be proposed

Pruritus and the risk of stretching are prevented using hydration and drugs. Capsaicin and cooling are frequently used to limit pain and inflammation. These programs are long, painful, and psychologically demanding. A limited compliance of the patients may explain some of the poor results sometimes observed, but most of the patients get benefit of these treatments.

Once the inflammation stage is completed, more active compressive techniques like endermology, motorized skin manipulations (LPG), stretching posture, high power jets, or other types of physiotherapy are proposed, with good results at 2 years. More than $90 \%$ of the patients come back to a normal function if the program is done properly. 


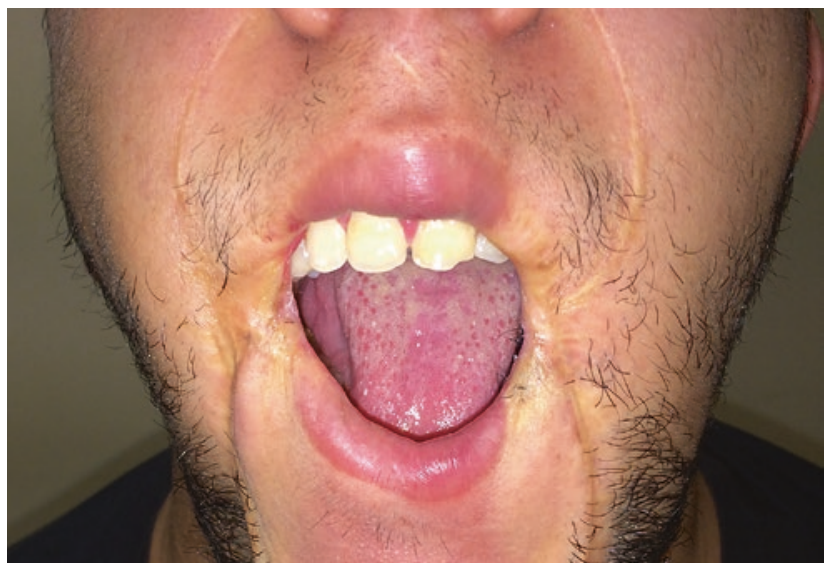

- Fig. 13.8 Bilateral contracture of the mouth web, combined with a red lip loss of substance. Surgery using W-Y-5 plasties, plus advancement of the mucosa will be proposed

Despite clear international recommendations [4] the studies on the modalities of application and the type of splints cover only a limited number of cases, therefore the evidence for these strategies is limited [5].

\subsection{Surgical Strategies}

Contracture release creates a large skin defect, and the aim of surgery is to restore as far as possible a full skin disponibility after surgery and to prevent recurrence.

\subsection{Z Plasties}

$\mathrm{Z}$ plasty is the most frequently used surgical technique [6]. Based on the principle of skin disponibility and softness of adjacent areas, the triangles designed by the Z-shape incisions break the linear scar contracture with a new scar without any mechanical tension. The cosmetic result is usually acceptable. Linear contractures are better managed using $\mathrm{Z}$ plasties, multiple $\mathrm{Z}$ plasties. Web contracture may be treated using W-Y 5 plasties combing $2 \mathrm{Z}$ plasties and an advancement flap, or omega plasties using the contracted skin but needing two small full skin grafts on the edges.

\subsection{Skin Grafts}

Skin grafts are by definition free skin transfers from one site to another without any vascular connection. Depending on their thickness, skin grafts form two different techniques, split-thickness skin grafts (STG) limited to epidermis and a thin layer of dermis, harvested using a dermatome and full-thickness skin grafts (FTG), which include the epidermis and the entire dermis; har- vested with a scalpel and needing a defatting before application. The donor sites of STG heal by rapid reepithelialization (like a superficial abrasion) while the donor site of FTG must be closed primarily for healing, so their use is limited to smaller defects. The main disadvantage of STG is the lack of dermal component, meaning a risk of recurrence higher than when using a flap.

\subsection{Dermal Substitutes}

Since three decades the introduction of acellular dermal substitute has changed the profile of skin grafting. The dermal component brought by the use of collagen (and elastin) inside the dermal substitute limits the secondary retraction of the thin skin graft applied to cover it, even if some shrinking is sometimes observed [7]. Different devices are proposed, with or without elastin, the collagen coming from different animals like cows, sharks, or pigs with different combination with elastin, and with or without a protective film in silicone, depending if the product is immediately covered by skin graft or secondarily after 3 weeks, the device being slowly incorporated in the new dermis before skin coverage. Hori et al. recently compared the contraction capacity, pores size, and shape of the different proposed devices [7] which may induce a secondary contraction.

\subsection{Flaps}

Large contractures have to be excised and replacement using different types of flaps.

Random skin flaps are frequently used [8], coming from the adjacent area when scar-free, but pedicled fasciocutaneous flaps bring a rich vascular network. Branches from this plexus reach the skin as direct or indirect perforators. They can be used locally or regionally, and rotated into the defect [9].

Perforator flaps, more recently developed, are based on a fine dissection of the perforator vessels going through the fascia to vascularize the overlying skin island. This increases the range of motion of these pedicled flaps and it reduces significantly the donor site morbidity.

Free flaps enlarge even further the armamentarium for tissue transfer. In principle, all axial flaps can be transferred as a free vascularized flap: the artery and the vein (eventually also the nerve) are transected at the donor site and re-anastomosed microsurgically with a recipient vessel at another part of the body. Till recently, free fasciocutaneous flaps and perforator flaps were most frequently used for coverage of contracture defects. Both can however result in significant donor site morbidity by harvesting structurally important fascia. 


\subsection{Conclusion}

In summary, contractures after burns are difficult to prevent, some areas like axilla, neck, and upper limbs being predominantly affected. Early skin grafting may prevent contractures, but an adapted rehabilitation program should be established and redefined during the regular check-up done by the burns team. When constituted, a precise analysis of the lacking skin surface should be done by the surgical team, issuing to a covering program depending on the area involved and the expertise of the team. Function may efficiently be restored using different techniques, skin grafting and dermal substitutes being more adapted in term of volumes, flap providing a suppler skin.

\footnotetext{
Take-Home Message

Contractures may form a severe functional deficit. Early prevention is mandatory, with a combination of exercise and positioning to prevent skin retraction. In specific situations like the burned hand immobilization can be done in both positions: flexion during the night and extension during the day. Treatment is difficult, and a balance should be sought between surgery, which always means a restart in the rehabilitation process, and the rehabilitation limits which should be established in close conjunction together with the team in charge. Recurrence is a risk if the postoperative management is not properly realized.
}

\section{References}

1. Kwan PO, Tredget EE. Etiological principles of scar and contracture. Hand Clin. 2017;33(2):277-92. https://doi.org/10.1016/j. hcl.2016.12.004. Epub 2017 Mar 1.

2. Schouten HJ, Nieuwenhuis MK, van Baar ME, van der Schans CP, Niemeijer AS, van Zuijlen PPM. The prevalence and development of burn scar contractures: a prospective multicenter cohort study. Burns. 2019;45(4):783-90. https://doi. org/10.1016/j.burns.2019.03.007, pii: S0305-4179(19)30144-5.

3. Thomas R, Wicks S, Toose C, Pacey V. Outcomes of early use of an end of range axilla orthotic in children following burn injury. J Burns Care Res. 2019;40(5):678-88. https://doi.org/10.1093/ jbcr/irz058.

4. Monstrey S, Middelkoop E, Vranckx JJ, Bassetto F, Ziegler UE, Meaume S, Téot L. Updated scar management practical guidelines: non-invasive and invasive measures. J Plast Reconstr Aesthet Surg. 2014;67:1017-25.

5. Richard R, Wards RS. Splinting and controversies. J Burn Care Rehabil. 2005;26(5):392-6.

6. Kim YH, Hwang KT, Kim KH, Sung IH, Kim SW. Application of acellular human dermis and skin grafts for lower extremity reconstruction. J Wound Care. 2019;28(Suppl 4):S12-7. https:// doi.org/10.12968/jowc.2019.28.Sup4.S12.

7. Hori K, Osada A, Isago T, Sakurai H. Comparison of contraction among three dermal substitutes: morphological differences in scaffolds. Burns. 2017;43(4):846-51. https://doi.org/10.1016/j. burns.2016.10.017. Epub 2016 Nov 17.

8. Hifny MA. The square flap technique for burn contractures: clinical experience and analysis of length gain. Ann Burns Fire Disasters. 2018;31(4):306-12.

9. Teot L, Bosse JP. The use of scapular skin island flaps in the treatment of axillary postburn scar contractures. Br J Plast Surg. 1994;47(2):108-11.

Open Access This chapter is licensed under the terms of the Creative Commons Attribution 4.0 International License (http://creativecommons. org/licenses/by/4.0/), which permits use, sharing, adaptation, distribution and reproduction in any medium or format, as long as you give appropriate credit to the original author(s) and the source, provide a link to the Creative Commons license and indicate if changes were made.

The images or other third party material in this chapter are included in the chapter's Creative Commons license, unless indicated otherwise in a credit line to the material. If material is not included in the chapter's Creative Commons license and your intended use is not permitted by statutory regulation or exceeds the permitted use, you will need to obtain permission directly from the copyright holder. 